\title{
Hyponatremia Revisited: Translating Physiology to Practice
}

\author{
Ewout J. Hoorn Robert Zietse \\ Department of Internal Medicine, Erasmus Medical Center, Rotterdam, The Netherlands
}

\section{Key Words \\ Hyponatremia • Vasopressin - Water balance regulation}

\begin{abstract}
The complexity of hyponatremia as a clinical problem is likely caused by the opposite scenarios that accompany this electrolyte disorder regarding pathophysiology (depletional versus dilutional hyponatremia, high versus low vasopressin levels) and therapy (rapid correction to treat cerebral edema versus slow correction to prevent osmotic demyelination, fluid restriction versus fluid resuscitation). For a balanced differentiation between these opposites, an understanding of the pathophysiology of hyponatremia is required. Therefore, in this review an attempt is made to translate the physiology of water balance regulation to strategies that improve the clinical management of hyponatremia. A physiologybased approach to the patient with hyponatremia is presented, first addressing the possibility of acute hyponatremia, and then asking if and if so why vasopressin is secreted non-osmotically. Additional diagnostic recommendations are not to rely too heavily of the assessment of the extracellular fluid volume, to regard the syndrome of inappropriate antidiuresis as a diagnosis of exclusion, and to rationally investigate the pathophysiology of hyponatremia rather than to rely on isolated laboratory values with arbitrary cutoff values. The features of the major hyponatremic disorders are
\end{abstract}

(c) 2008 S. Karger AG, Basel $1660-2137 / 08 / 1083-0046 \$ 24.50 / 0$

Fax +41613061234

E-Mail karger@karger.ch

www.karger.com
Accessible online at:

www.karger.com/nep discussed, including diuretic-induced hyponatremia, adrenal and pituitary insufficiency, the syndrome of inappropriate antidiuresis, cerebral salt wasting, and exercise-associated hyponatremia. The treatment of hyponatremia is reviewed from simple saline solutions to the recently introduced vasopressin receptor antagonists, including their promises and limitations. Given the persistently high rates of hospital-acquired hyponatremia, the importance of improving the management of hyponatremia seems both necessary and achievable.

Copyright $\odot 2008$ S. Karger AG, Basel

\section{Introduction}

Hyponatremia is the most commonly encountered electrolyte disorder in clinical medicine, and occurs in approximately one of every three hospitalized patients [1]. Hyponatremia is defined as a decreased serum sodium concentration (usually below $136 \mathrm{mmol} / \mathrm{l}$ ) and always implies that there is water in excess of sodium. The presence of hyponatremia is therefore primarily a reflection of a disturbance in water rather than sodium balance, although several interactions between the two regulatory systems exist. Because the definition of hyponatremia is based on a concentration, it does not provide information on the filling of the extracellular fluid volume (ECF) in 
which sodium is measured. In fact, hyponatremia can occur in the context of a contracted ECF (hypovolemia), normal ECF (normovolemia) or expanded ECF (hypervolemia) [2]. The fact that completely different pathophysiological settings can present with hyponatremia emphasizes the importance of a careful diagnostic approach in order to select adequate therapy. The reason that hyponatremia requires treatment is that the relative excess of water lowers serum osmolality (of which sodium is the most important determinant), causing a shift of water into cells until new osmotic equilibrium is reached. Although hyponatremia will cause all cells to swell, brain cell swelling is especially dangerous because the rigid box of the skull limits space for expansion. The ramifications of hyponatremia for the brain are twofold: cerebral edema if hyponatremia develops quickly (acute hyponatremia), or osmotic demyelinization if chronic hyponatremia is corrected too quickly after brain cells have adapted to their hypotonic environment [2]. The complexity of hyponatremia as a clinical problem and the opposite choices that are involved (e.g., fluid resuscitation vs. fluid restriction, quick vs. slow correction) sometimes results in inadequate management including delayed therapy, iatrogenic damage, and increased healthcare costs $[1,3]$. One solution to this problem could be to select a more physiological approach to hyponatremia [4]. Therefore, in this review an attempt is made to translate the pathophysiological principles of hyponatremia to strategies that may improve its clinical management. Bearing this in mind, an overview of the hyponatremic disorders and their treatment is given, emphasizing novel insights such as exercise-associated hyponatremia, the nephrogenic syndrome of inappropriate antidiuresis, and vasopressin receptor antagonists that have recently become available.

\section{The Pathophysiology of Hyponatremia}

\section{Water Balance Regulation: The Brain-Kidney}

Connection

Water balance regulation depends on an interaction between specialized sensors that translate the signals they receive (high serum osmolality, low effective circulating volume) to the central release of arginine vasopres$\sin$ (the antidiuretic hormone) into the circulation, which then stimulates water reabsorption in the renal collecting duct. Figure 1 shows how water balance regulation is disturbed during hyponatremia, but also provides an overview of the regulatory system during normal physiology.

Hyponatremia: From Pathophysiology to Management
Water balance regulation is primarily designed to control serum osmolality and to a lesser extent blood volume (vasopressin starts to rise after a $1 \%$ increment in serum osmolality vs. a $5-10 \%$ decrease in blood volume). The serum osmolality is sensed by osmoreceptors in several parts of the brain, including the supraoptic nuclei of the hypothalamus, the subfornical organ, and the organum vasculosum of the lamina terminalis (fig. 1) [5, 6]. A rise in serum osmolality causes water to move through the water channels of the osmoreceptor cell membranes, which then causes a change in cell volume. This leads to an increase in the activity of stretch-inhibited cation channels (including the $\mathrm{N}$-terminal variant of the transient receptor potential vanilloid type-1 [7]), affecting membrane voltage and ultimately the action potential discharge [8]. The accelerated action potential discharge causes an influx of calcium through a voltage-gated calcium channel which triggers a cascade of molecular events that ultimately leads to the neurosecretion of secretory vesicles containing vasopressin into the bloodstream (fig. 1) [9]. On the other hand, the carotid sinus baroreceptors sense a low effective circulating volume, and parasympathetic afferents transfer this signal to the vasomotor center, which increases the rate of vasopressin secretion by the cells in the paraventricular nuclei (fig. 1). Once released into the circulation, vasopressin can activate three types of G-coupled receptors, including V1a (vascular and hepatic), V1b (anterior pituitary), and V2 (renal collecting duct). The activation of the vasopressin2 receptor V2R by vasopressin stimulates an intracellular cascade, which ultimately results in the insertion of aquaporin (AQP)-2 (AQP2) water channels in the apical membrane (fig. 2 shows this process by electron microscopy). The presence of AQPs in combination with an osmotic gradient allows water to move through the principal cell, returning to the basolateral bloodstream via the constitutively expressed AQP3 and AQP4 water channels [10]. Vasopressin also increases sodium and urea permeability in the collecting duct (by increasing the number of the epithelial sodium channel, $\mathrm{ENaC}$, and the urea transporter, UT-A1), thereby maintaining the osmotic and medullary interstitial gradients and further stimulating antidiuresis [11]. Short-term control of water permeability is achieved through trafficking of AQP2-containing vesicles to the apical membrane, whereas long-term control influences the abundance of the AQP2 protein. The molecular machinery of this V2R-AQP2 cascade is increasingly being unraveled. The current understanding of this cascade is that stimulation of the V2R by vasopressin activates the Gs adenylyl cyclase system, stimulating 


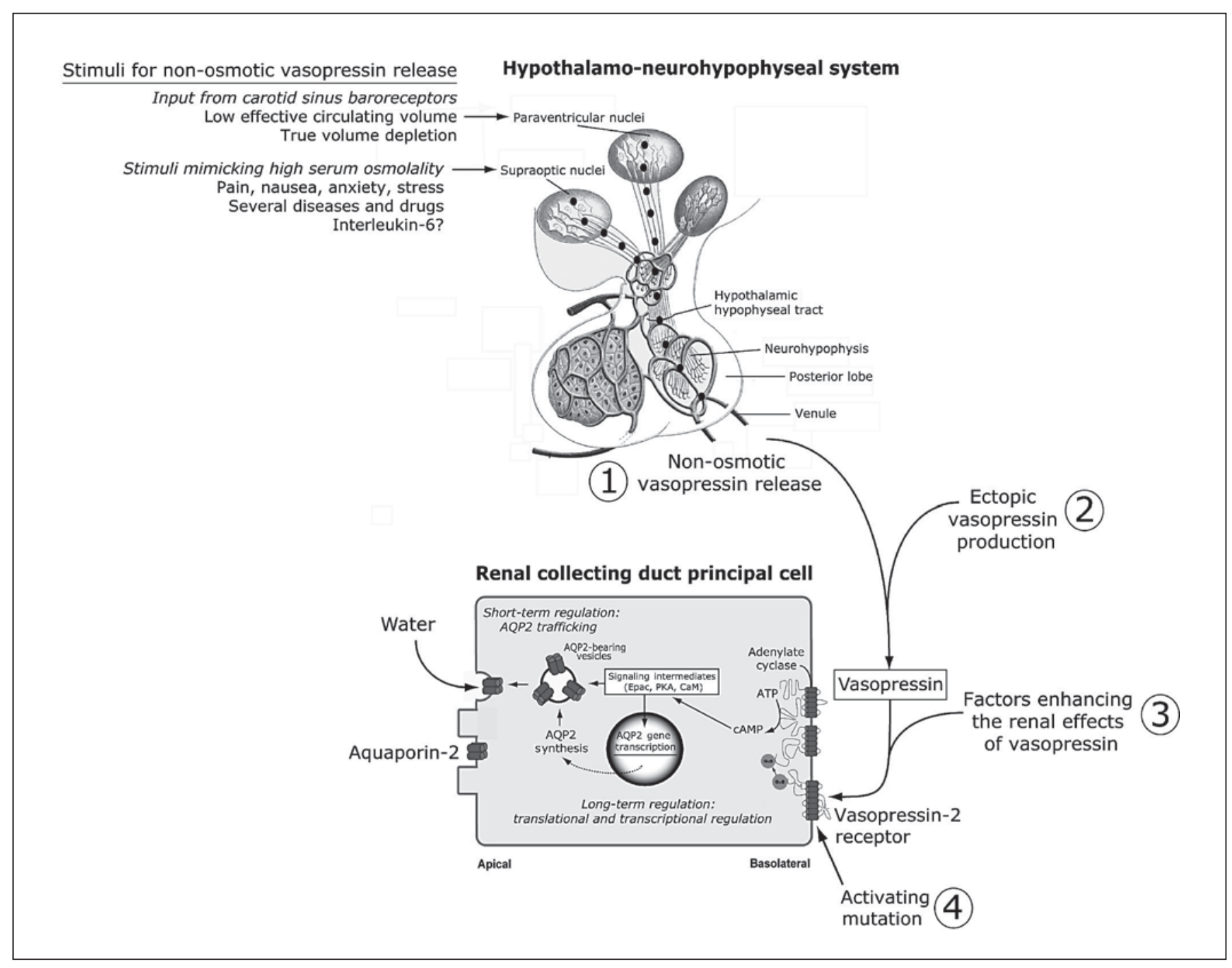

Fig. 1. The pathophysiology of vasopressin during hyponatremia. In the majority of patients, hyponatremia develops because vasopressin is secreted non-osmotically resulting in renal water reabsorption. The figure shows the four mechanisms that can cause this effect: (1) non-osmotic vasopressin release by the posterior pituitary induced by specific stimuli from the paraventricular or supraoptic nuclei; (2) ectopic vasopressin production; (3) factors

cAMP and protein kinase A (PKA), which triggers the phosphorylation of many proteins including AQP2 [10]. However, several other signaling pathways have been implicated in the V2R-AQP2 cascade, involving for example PKA-independent pathways [12], calcium-calmodulin [13], Rho, soluble N-ethylmaleimide-sensitive factor attachment receptors (SNARE) proteins, cAMP responsive element-binding protein (CREB) and extracellular signal-regulated kinase (ERK) [13]. that may enhance the renal effects of vasopressin, and, finally, (4) a vasopressin-like effect caused by an activating mutation of the vasopressin-2 receptor. In addition, details of the hypothalamoneurohypophyseal system and the intracellular signaling cascade in the renal collecting duct principal cell are shown. The illustration of the hypothalamo-neurohypophyseal system was adapted from Patel and Balk [74], with kind permission.

\section{Hyponatremia: Non-Osmotic Vasopressin Release and Its Escape}

The presence of hyponatremia nearly always implies that vasopressin is released non-osmotically, thereby preventing the excretion of electrolyte-free water, and diluting the serum sodium concentration. For example, Anderson et al. [14] showed that non-osmotic vasopressin secretion was present in $97 \%$ of hyponatremic patients studied. Causes of non-osmotic vasopressin release in- 


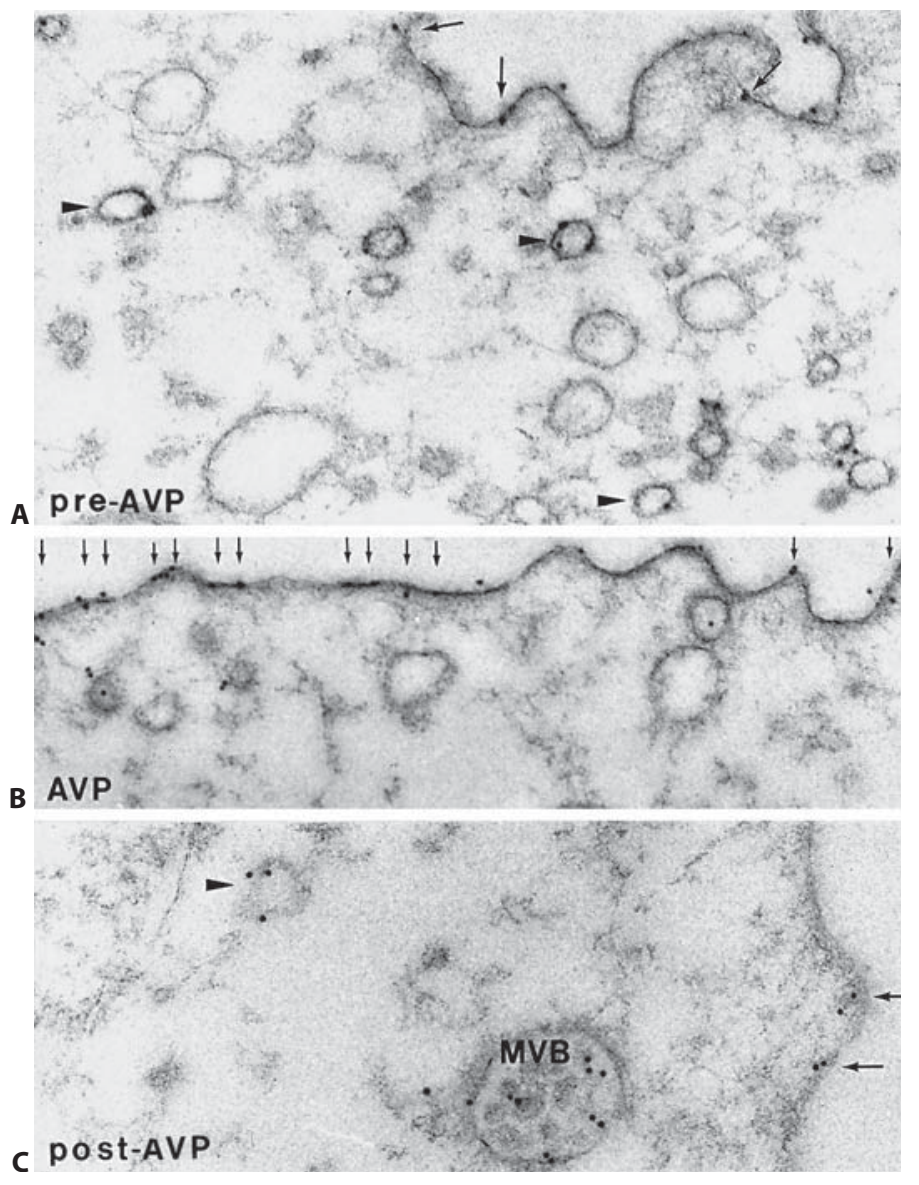

Fig. 2. Immuno-gold localization of aquaporin-2 (AQP2) in renal collecting ducts before, during and after stimulation with arginine vasopressin (AVP). Electron microscopy images showing immuno-gold localization of the water channel AQP2 in isolated perfused tubules of the renal collecting duct principal cell. A The basal condition (pre-AVP, osmotic water permeability $65 \mu \mathrm{m} / \mathrm{s}$ ) with AQP2 mainly localized in vesicles (arrowheads). B Stimulation with arginine vasopressin (AVP, osmotic water permeability $454 \mu \mathrm{m} / \mathrm{s}$ ) and the insertion of AQP2 in the apical plasma membrane (multiple arrows) is illustrated. C The situation after stimulation with arginine vasopressin (post-AVP, osmotic water permeability $204 \mu \mathrm{m} / \mathrm{s}$ ) with AQP2 again mainly localized in vesicles, including multi-vesicular bodies (MVB). This picture is courtesy of Dr. Søren Nielsen (University of Aarhus, Denmark) and Dr. Mark Knepper (National Institutes of Health, USA).

clude a low effective circulating volume, several diseases and drugs, and nonspecific stimuli such as anxiety, stress, pain, and nausea (fig. 1). Apart from the increased production of vasopressin, vasopressin can also be produced ectopically (e.g., in small cell lung cancer), its renal effects can be enhanced with normal vasopressin levels (e.g., by cyclophosphamide), or a vasopressin-like effect can oc- cur in the absence of vasopressin (e.g., through an activating mutation of the V2R; fig. 1) [15]. Although many of the pathways that influence central non-osmotic vasopressin release are unknown, there is increasing evidence for a relationship between high interleukin- 6 levels and vasopressin release [16]. Interleukin- 6 appears to take the same secretory pathway as vasopressin [17] and interleukin- 6 receptors and signal-transducing units exist in the hypothalamo-neurohypophyseal system [18]. We recently showed a direct relationship between a rise in C-reactive protein and the development of hyponatremia [19], suggesting that the acute-phase response, perhaps through interleukin-6, could explain the established relationship between certain infections and hyponatremia.

There may have been an evolutionary benefit for the non-osmotic release of vasopressin to conserve water during times of severe volume depletion or infection. To date, however, the non-osmotic release of vasopressin is often unwanted (for example because it is paraneoplastic or drug-related), and may give rise to the syndrome of inappropriate antidiuresis (SIAD). It is important to realize that the actual development of hyponatremia always requires the ongoing consumption of water, which in humans is often socially determined rather than thirst driven (conversely, it is difficult to induce hyponatremia in animals). However, a defense mechanism exists to limit the degree of hyponatremia when vasopressin levels are persistently high and water is ingested continuously. 'Escape' from vasopressin-induced antidiuresis is an important physiological response, during which water diuresis develops despite high circulating levels of vasopressin [10]. The renal mechanisms of vasopressin escape include not only a downregulation of AQP2 (through a combination of V2R internalization and transcriptional and translational regulation of AQP2), but also of the epithelial sodium channel $\mathrm{ENaC}$ and the urea transporter UT-A3, which may contribute to a solute diuresis [20].

\section{A Physiology-Based Approach to Hyponatremia}

Recently, we evaluated the validity and accuracy of the existing clinical diagnostic algorithms for hyponatremia [4] which are commonly used in the diagnostic approach to hyponatremia. Three main weaknesses were identified including a failure to consider acute hyponatremia, a tendency to diagnose SIAD prior to excluding other causes of hyponatremia, and too much emphasis on the clinical assessment of the ECF [4]. 
Fig. 3. A Diagnostic approach to hyponatremia: first determine the acuity.

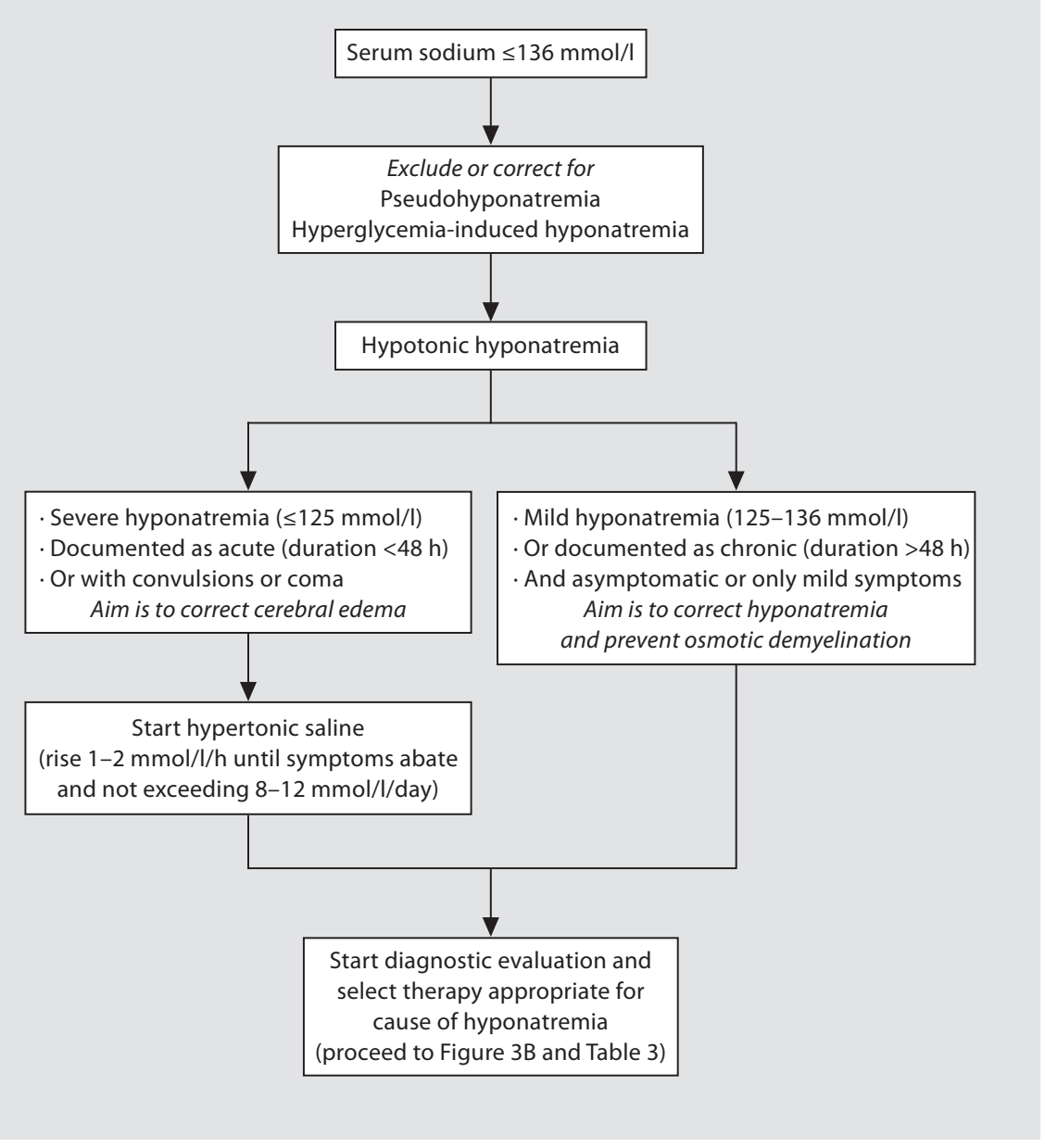

To overcome some of these limitations, a more physiology-based approach was proposed, in which the possibility of acute hyponatremia was considered first, and subsequently an analysis was made if and why vasopressin levels are elevated. Figure 3 shows a modified version of this algorithm [4], while table 1 summarizes the general recommendations. More recently, others have also emphasized the importance of recognizing and treating acute hyponatremia prior to proceeding with further diagnostic evaluation [21]. Moreover, if time permits, the possibilities of pseudohyponatremia and hyperglycemiainduced hyponatremia should also be considered (by measuring serum osmolality and serum glucose), because these causes of hyponatremia require no or different treatment (fig. 3A).

Acute hyponatremia is defined as the development of symptomatic hyponatremia of $125 \mathrm{mmol} / \mathrm{l}$ or less within $48 \mathrm{~h}$. A history of polydipsia or another obvious source of electrolyte-free water (e.g., hypotonic intravenous fluids) often precedes the presentation of acute hyponatremia. However, its differentiation from chronic hyponatremia remains a challenge because the early symptoms of acute hyponatremia are nonspecific (nausea, vomiting, headache, confusion) and the patient usually presents hyponatremia without documentation of the previous course in serum sodium. Hsu et al. [22] identified 1,321 patients with hyponatremia in a 2-year retrospective study, 11 of whom were found to have acute hyponatremia (mean serum sodium $115 \mathrm{mmol} / \mathrm{l}$, average fluid intake 5 liters/ day). They identified low serum urea and uric acid concentrations and increased fractional excretions of both as biochemical abnormalities accompanying acute hyponatremia which were attributed to an effect of acute volume expansion [22]. When assessing acute hyponatremia, it is important to note that the venous serum sodium concentration can be appreciably higher than the arterial sodi- 


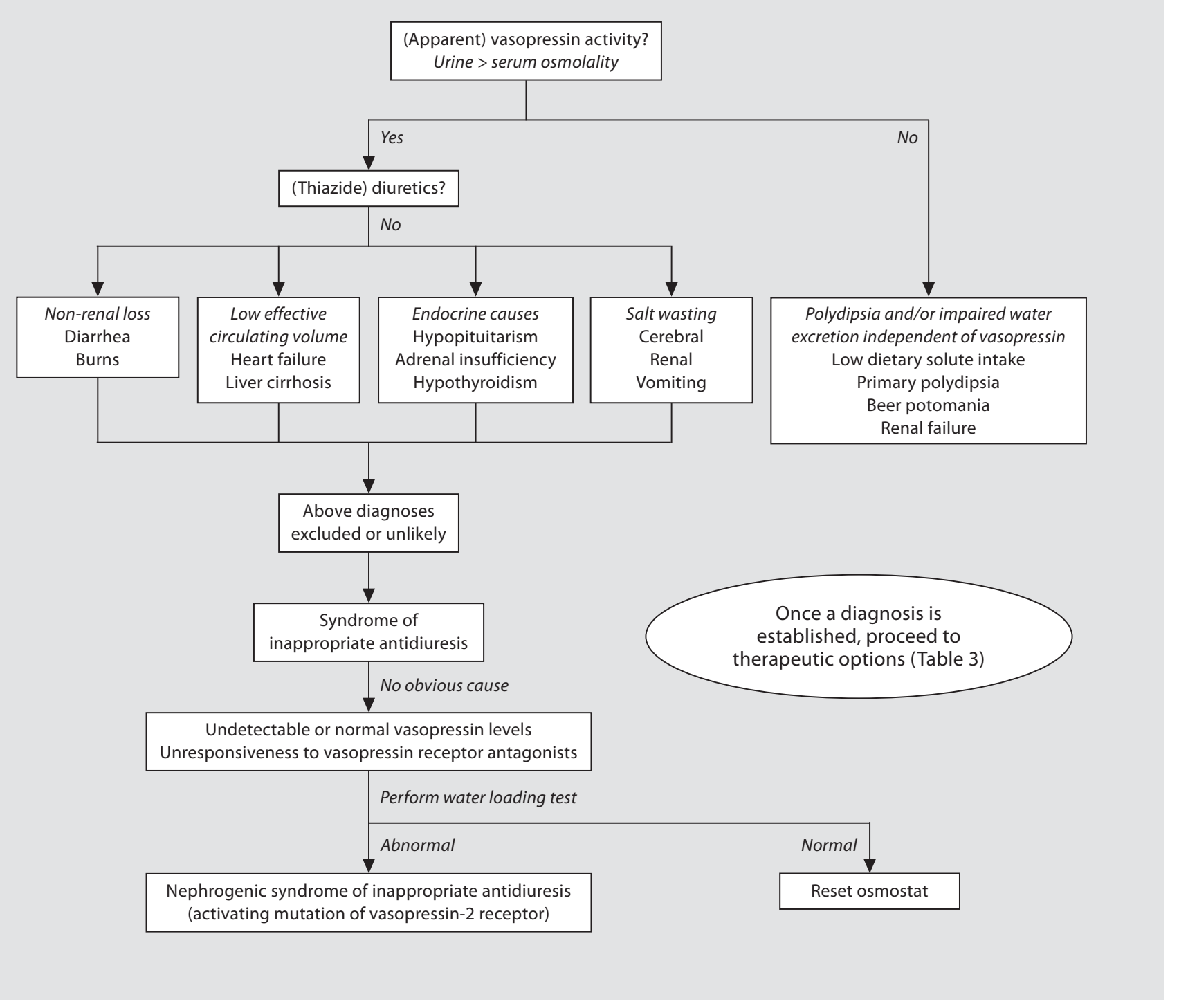

Fig. 3. B Diagnostic approach to hyponatremia: evaluate if and if so why vasopressin is acting.

um concentration (which determines the effect on the brain), especially when water absorption is rapid [23, 24].

Once acute hyponatremia has been dealt with, further diagnostic evaluation should take place. In our opinion, the next relevant question should be if and if so why vasopressin is released non-osmotically. If vasopressin is acting, the urine osmolality usually exceeds the serum osmolality. However, because hypoosmolality should normally lower urine osmolality to below $100 \mathrm{mosm} / \mathrm{kg}$, it should be borne in mind that urine osmolalities be- tween 100 and $300 \mathrm{mosm} / \mathrm{kg}$ could still suggest vasopressin action, although other factors such as high water intake or low osmotic intake are usually necessary to cause overt hyponatremia. The comparison between serum and urine osmolality may replace the actual measurement of vasopressin, which is not routinely performed in the analysis of hyponatremia.

If it is likely that vasopressin is acting, several important causes of hyponatremia with elevated levels of vasopressin should be considered, including the use of diuretics, pituitary, adrenal and thyroid insufficiency, heart 
Table 1. Diagnostic considerations in the approach to hyponatremia

1 In acute and symptomatic hyponatremia, therapy precedes diagnosis

2 The symptoms of hyponatremia are: nausea and vomiting $(<136 \mathrm{mmol} / \mathrm{l})$, cognitive impairment $(<136 \mathrm{mmol} / \mathrm{l})$, confusion $(<131 \mathrm{mmol} / \mathrm{l})$, seizures $(<125 \mathrm{mmol} / \mathrm{l})$, noncardiogenic pulmonary edema $(<125 \mathrm{mmol} / \mathrm{l})$, coma $(<117 \mathrm{mmol} / \mathrm{l})$, and death (depending on therapy)

3 Chronic hyponatremia is also associated with other neurological impairments, such as falls, gait disturbances, and attention deficits

4 Pseudohyponatremia (still possible with ion-selective electrodes) and hyperglycemia-induced hyponatremia should be considered early during the diagnostic process

5 Hyponatremia usually means high vasopressin levels - the diagnostic process should focus on the reason why these levels are elevated

6 The clinical assessment of the extracellular fluid volume should not be a determining factor in the differentiation of hyponatremia

7 Hypopituitarism and primary adrenal insufficiency are often overlooked, the latter because hyperkalemia may be absent and random cortisol levels may be normal

8 The syndrome of inappropriate antidiuresis should only be diagnosed after excluding diuretic use, thyroid, adrenal, and pituitary insufficiency

9 If all else fails, calculate a 'tonicity balance' with separate mass balances for water and sodium plus potassium

and liver failure, cerebral and renal salt wasting, and nonrenal sodium loss. In fact, by the definition of Janicic and Verbalis [25], these causes should all be excluded prior to considering the diagnosis of SIAD (fig. 3B). Usually, an analysis of medication (thiazide use), physical examination (edema in heart and liver failure), clinical setting (cerebral salt wasting in subarachnoid hemorrhage), symptomatology (vomiting, diarrhea) or laboratory tests (low cortisol in adrenal and pituitary insufficiency) are sufficient to steer the differentiation between these hyponatremic disorders.

Of the endocrine disorders associated with hyponatremia, especially primary adrenal insufficiency is often missed, possibly because hyperkalemia is absent in a third of the cases [26], and because random cortisol measurements may be misinterpreted [27]. Smith et al. [27] therefore recommended having a low threshold for per- forming the short corticotrophin test in patients with unexplained hyponatremia. Hypopituitarism with secondary adrenal insufficiency is another overlooked cause of hyponatremia [28], and might be differentiated from SIAD by the presence of a compensated respiratory alkalosis (possibly due to subclinical cerebral edema) with a low plasma bicarbonate (possibly due to aldosterone deficiency) and low carbon dioxide levels [29]. The relationship between hypothyroidism and hyponatremia, although described in every textbook, was recently questioned by Warner et al. [30]. Although they showed a statistical association between hyponatremia and hypothyroidism (for every $10 \mathrm{mU} / \mathrm{l}$ rise in thyroid-stimulating hormone, serum sodium decreased $0.14 \mathrm{mmol} / \mathrm{l}$ ), the clinical relevance of this association seems minute. If the relationship does exist, a low cardiac output (stimulating volume-mediated vasopressin release) and/or a low glomerular filtration rate (low distal delivery diminishes free water excretion) could explain its pathophysiology.

If other hyponatremic disorders are unlikely or excluded and SIAD is suspected, a careful analysis should be made if the patient is taking any drugs or has any underlying disease that has ever been associated with SIAD [21]. If no obvious cause for SIAD is found, further testing may be necessary by measuring vasopressin and performing a water loading test (which is normal when $\geq 80 \%$ of a $15-\mathrm{ml} / \mathrm{kg}$ water load is excreted in $4 \mathrm{~h}$ ) [31,32]. If vasopressin levels are undetectable and water is retained, this could indicate nephrogenic SIAD due to an activating mutation of the V2R, a recently discovered and novel cause of hyponatremia [15]. If vasopressin levels are normal and water is also excreted normally, a reset osmostat should be considered. Another clue is that vasopressin-receptor antagonists will not provoke a response in both nephrogenic SIAD and reset osmostat (fig. 3B).

Several other parameters in serum and urine may assist in the diagnostic approach to hyponatremia, including osmolality, sodium, chloride, potassium, creatinine, urea, uric acid, and acid-base (table 2). Our recommendation is to use these parameters as supportive rather than decisive indices, because they may be influenced by other factors, and because their sensitivity and specificity has never been formally assessed.

An underappreciated, but interesting diagnostic parameter is uric acid. As mentioned, low uric acid levels are associated with volume expansion in general and SIAD in particular (except in the elderly) [22]. Volume expansion increases uric acid clearance and reduces its reabsorption secondary to a reduction in proximal sodium reabsorption. Furthermore, stimulation of the V1a 
receptor may also contribute to renal uric acid loss, because in experimental hyponatremia, hypouricemia is less pronounced when it is induced by V2R-specific stimulation (using dDAVP) compared to stimulation of both the $\mathrm{V} 1 \mathrm{a}$ and $\mathrm{V} 2$ receptors [33]. In addition, Maesaka et al. $[34,35]$ have advocated the diagnostic value of uric acid in the differentiation between hyponatremia due to SIAD and hyponatremia due to renal salt wasting. The response to treatment may differentiate the two underlying disorders because in their case series water restriction corrected both hypouricemia and hyponatremia in SIAD, whereas isotonic fluid resuscitation corrected hyponatremia, but not hypouricemia in renal salt wasting. According to Maesaka et al. [34,35], the basis of renal sodium (and uric acid) wasting in these patients was a (partial) Fanconi syndrome, as it was also associated with phosphaturia.

Another critique on the existing clinical diagnostic algorithms for hyponatremia is their emphasis on the assessment of the ECF, while any proven reliability in the literature is lacking. For example, Chung et al. [36] showed that the clinical assessment of hyponatremic patients correctly identified only $47 \%$ of hypovolemic patients, and $48 \%$ of normovolemic patients. In a systematic review, McGee et al. [37] showed that the diagnostic accuracy of physical signs varied greatly for hypovolemia not due to blood loss. Few physical signs had proven utility, and an analysis based on serum electrolytes, creatinine, and urea seemed superior [37]. Our opinion is that the extracellular volume status should still be routinely assessed in patients with hyponatremia, but that this information should not be the first or a determining factor, as is currently the case in many algorithms [4, 38].

Finally, when several diagnostic approaches have been fruitless and hyponatremia is still unexplained (a familiar situation for many physicians), another useful approach may be to pursue a quantitative analysis by calculating separate mass balances for water and sodium plus potassium in a so-called 'tonicity balance' [39].

\section{The Hyponatremias: Overview of Hyponatremic Disorders}

Below a synopsis of the main hyponatremic syndromes is provided.

\section{Pseudohyponatremia}

Pseudohyponatremia may still occur despite the use of ion-selective electrodes [40]. Two of the three methods

Hyponatremia: From Pathophysiology to Management
Table 2. Useful diagnostic parameters in the differentiation of hyponatremia

\begin{tabular}{ll}
\hline $\begin{array}{l}\text { Diagnostic } \\
\text { parameter }\end{array}$ & Interpretation \\
\hline Serum osmolality \\
High & Hyperglycemia, glycine solutions \\
Normal & Pseudohyponatremia \\
Low & Hypotonic hyponatremia \\
\hline
\end{tabular}

Urine osmolality

High $^{1} \quad$ Vasopressin-dependent cause of hyponatremia

Low ${ }^{1} \quad$ Vasopressin-independent cause of hyponatremia

Urine sodium

Low Heart or liver failure, polydipsia, non-renal

sodium loss, true volume depletion

High Diuretics, cerebral and renal salt wasting, SIAD, primary adrenal insufficiency, hypopituitarism

\begin{tabular}{cl}
\hline \multicolumn{2}{l}{ Serum potassium } \\
Low & Diuretic use, vomiting, diarrhea \\
High & Primary adrenal insufficiency, renal failure \\
\hline $\begin{array}{c}\text { Serum urea } \\
\text { Low }\end{array}$ & SIAD, acute volume expansion \\
\hline
\end{tabular}

Serum uric acid

Low SIAD, renal salt wasting, acute volume expansion

\begin{tabular}{cl}
\hline Alkalosis & \\
Metabolic & Diuretic use, vomiting \\
Respiratory & Hypopituitarism \\
\hline Acidosis & \\
Metabolic & $\begin{array}{l}\text { Primary adrenal insufficiency, diarrhea, renal } \\
\text { failure }\end{array}$
\end{tabular}

${ }^{1}$ Compared to serum osmolality.

for determining the serum sodium concentration (flame photometry and indirect potentiometry) use sample dilution, which can artefactually lower the serum sodium concentration in situations when serum water is displaced by elevated concentrations of lipids or proteins [41]. Clinically, pseudohyponatremia can therefore occur during conditions such as hyperlipemic pancreatitis, multiple myeloma, or even hypercholesterolemia [40]. Measuring serum osmolality and arterial serum sodium using a blood gas analyzer (direct potentiometry without sample dilution) are two ways to assess whether pseudohyponatremia is present.

\section{Hyperglycemia-Induced Hyponatremia}

Glucose is an effective osmole, and can therefore attract water from the intracellular to the extracellular 
compartment. The early recognition of hyperglycemiainduced hyponatremia is important because the shift of water is exactly opposite to most of the other hyponatremic disorders. Correction factors exist to assess if the degree of hyperglycemia can explain the degree of hyponatremia, and the ones reported vary between a 1.6and $2.4-\mathrm{mmol} / \mathrm{l}$ fall in natremia for every $5 \mathrm{mmol} / \mathrm{l}$ rise in glycemia [42].

\section{Diuretic-Induced Hyponatremia}

Diuretic-induced hyponatremia is probably the most common hyponatremic disorder encountered in clinical medicine, and is mainly associated with the use of thiazide diuretics. Although the inhibition of the sodiumchloride co-transporter by thiazides and the consequent renal sodium loss and volume depletion obviously contribute to hyponatremia, it is not the only factor. This is illustrated by the fact that patients with Gitelman's syndrome, who have an inactivating mutation of the transporter, do not exhibit hyponatremia. Although this may be chronic adaptation, there is also evidence that thiazides may directly stimulate the non-osmotic release of vasopressin [43]. Risk factors for thiazide-induced hyponatremia are age (although not a risk factor according to Sonnenblick et al. [44]), gender, hypokalemia, and a low lean body mass, while the concomitant use of loop diuretics, angiotensin-converting enzyme inhibitors, or nonsteroidal anti-inflammatory drugs were not identified as risk factors [44, 45]. Interestingly, Friedman et al. [46] showed that a single dose of a thiazide diuretic may predict the development of hyponatremia because it produced a $5.5-\mathrm{mmol} / \mathrm{l}$ fall in serum sodium associated with weight gain in patients with thiazide-induced hyponatremia compared to a 1.2 - and $1.8-\mathrm{mmol} / \mathrm{l}$ fall in serum sodium and weight loss in healthy controls or elderly hypertensive patients.

\section{Syndrome of Inappropriate Antidiuresis}

As discussed in a recent review [21], the causes of SIAD are myriad, and for the sake of clarity they are best categorized into pulmonary disorders, malignant diseases, disorders of the nervous system, and drug-induced SIAD. Robertson [47] identified four patterns of SIAD including unregulated vasopressin secretion, elevated basal secretion of vasopressin despite normal regulation by osmolarity, a 'reset osmostat' (described in pregnancy, cancer, psychosis, malnourishment, and tuberculosis), and undetectable vasopressin levels, as is found in nephrogenic SIAD.

\section{Nephrogenic SIAD}

A conceptually interesting and novel hyponatremic disorder was recently described in two male children by Feldman et al. [15]; it was caused by an activating mutation of the V2R. The two children presented with the phenotype of classic SIAD (hyponatremia, high urinary sodium and osmolality, normovolemia), but without detectable vasopressin levels. Since this initial discovery, the responsible activating missense mutation $\mathrm{R} 137 \mathrm{C}$ has also been identified in pediatric and adult males and females [31]. Nephrogenic SIAD should therefore be suspected in any patient with therapy-resistant hyponatremia, undetectable vasopressin levels, unresponsiveness to vasopressin-receptor antagonists and an abnormal response to a water-loading test (fig. 3B).

\section{Cerebral Salt Wasting}

Cerebral salt wasting is incompletely understood, but the best data on the possible mechanisms come from Berendes et al. [48] who compared patients who had surgery for subarachnoid hemorrhage to patients who had brain tumor surgery. Postoperatively, subarachnoid hemorrhage patients developed polyuria and a natriuresis that correlated with increased B-type natriuretic peptide levels. Throughout the postoperative course, B-type natriuretic peptide was elevated, while aldosterone was suppressed, both contributing to the natriuresis. Vasopressin levels were only briefly elevated, both before and after surgery. Intriguingly, none of the patients developed hyponatremia, which was attributed to tailored saline resuscitation. This emphasizes that hyponatremia is not a prerequisite for the diagnosis cerebral salt wasting, but may be more the result of inadequate fluid management.

\section{Hypopituitarism and Primary Adrenal Insufficiency}

Hypopituitarism and primary adrenal insufficiency (Addison's disease) are rare but often missed causes of hyponatremia. Hypopituitarism causes hyponatremia primarily because adrenocorticotropin hormone deficiency causes cortisol deficiency which in turn can cause the inappropriate secretion of vasopressin. In primary adrenal deficiency, not only cortisol deficiency but also aldosterone deficiency contribute to hyponatremia, which is why hyperkalemia may also be present. Hypopituitarism can be caused by pituitary or hypothala mic diseases (tumors, trauma, infection, infarction, radiation, surgery). Primary adrenal insufficiency is often caused by autoimmune adrenalitis, but can also be caused by destruction of the adrenal glands by a metastasis or adrenal 
infections, for example in the acquired immunodeficiency syndrome [27].

\section{Hyponatremia in Heart and Liver Failure}

Heart failure (low cardiac output) or liver failure (systemic vasodilatation) both lead to a low effective arterial blood volume $[49,50]$. As a response to the reduced baroreceptor activity, the renin angiotensin system is activated first, whereas the vasopressin axis is activated after a greater decrease in arterial filling. The development of hyponatremia during heart or liver failure is a poor prognostic sign, and hyponatremia has emerged as an independent predictor for mortality from several epidemiological studies [51, 52]. Interestingly, hyponatremia was recently also found to be a predictor of long-term mortality and admission for heart failure after hospital discharge in survivors of acute ST-elevation myocardial infarction [53]. The explanation for these associations is probably not so much a direct effect of hyponatremia, but rather hyponatremia being a marker for the extent of the so-called 'neurohumoral response', and therefore the degree of decompensation. The central role of hyponatremia in this neurohumoral response has clearly been demonstrated in heart and liver failure, in which hyponatremia correlated with the activity of the renin angiotensin and prostaglandin systems $[54,55]$. The neurohumoral response probably also explains why a deterioration of hyponatremia in heart and liver failure coincides with a deterioration in renal function [56].

\section{Exercise-Associated Hyponatremia}

Although the first report of exercise-associated hyponatremia dates from 1985 [57], there has been renewed attention to this disorder since Almond et al. [58] reported a $13 \%$ incidence of hyponatremia in runners of the Boston marathon. An even larger and perhaps mechanistically more interesting study was performed by Noakes et al. [59] who measured post-race body weight changes in 2,153 athletes. Based on their data, three independent biological mechanisms for exercise-associated hyponatremia were postulated, namely excessive fluid intake, inappropriate vasopressin activity, and interactions between osmotically active and inactive sodium stores. Excessive fluid intake may represent learned behavior to prevent 'dehydration', or it could be the result of true thirst, for example because of high angiotensin II or low potassium levels (both reported during exercise and both strong thirst stimuli [60]). An interesting novel explanation for inappropriate vasopressin excretion during exercise was recently described by Siegel et al. [61] who re-

Hyponatremia: From Pathophysiology to Management ported a fortyfold increase in interleukin- 6 in marathon runners, which can directly stimulate vasopressin release [16]. The evidence for a role of osmotically inactive sodium stores comes from the fact that $70 \%$ of the athletes in the study by Noakes et al. [59], who overconsumed hypotonic fluids, increased body weight without becoming hyponatremic. A possible explanation could be the osmotic activation of sodium from exchangeable stores or the ability to prevent or undo the inactivation of sodium during exercise [59].

\section{Polydipsia and Low Solute Intake}

The pathophysiology of the remaining hyponatremic disorders, water polydipsia, beer polydipsia, and hyponatremia due to a low dietary solute intake ('tea and toast'), is independent of vasopressin (fig. 3B). Instead, their pathophysiology is explained by polydipsia in combination with solute loss or low solute intake. Thaler et al. [62] demonstrated that electrolyte-free water excretion depends not only on the osmolality and sodium plus potassium content of the urine, but also on the total rate of solute excretion. Therefore, during a low dietary solute intake, solute excretion (mainly urea) can become the rate-limiting step for electrolyte-free water excretion. In this situation, amounts of fluid that are below the water excretory capacity of the kidneys (15-20 liters/day) can already cause hyponatremia. Similarly, Musch et al. [63] demonstrated that in hyponatremia due to polydipsia, water intake alone was insufficient to explain the degree of hyponatremia, and that the apparent loss of solutes (possibly through an unknown renal route) played a significant contributory role.

\section{Treating Hyponatremia}

Acute hyponatremia should be treated swiftly to prevent cerebral edema, while chronic hyponatremia should be treated slowly to avoid the osmotic demyelination syndrome [2]. Despite the elegant simplicity of this adage, correcting hyponatremia is like sailing between Scylla and Charybdis because the acuity of hyponatremia is often unknown, both slow and rapid correction of hyponatremia can cause serious neurological damage, and there are no results from randomized clinical trials to guide the treatment of hyponatremia $[21,38]$. Second best are therefore authority-based guidelines, which advise to correct acute hyponatremia with $1-2 \mathrm{mmol} / \mathrm{l} / \mathrm{h}$ until symptoms abate, but not to exceed an $8-10 \mathrm{mmol} / \mathrm{l}$ rise for the first $24 \mathrm{~h}$, and $18-25 \mathrm{mmol} / \mathrm{l}$ for the first $48 \mathrm{~h}$ [21]. Chronic 
Table 3. Treatment of hyponatremia

\begin{tabular}{ll}
\hline Hyponatremic disorder & Therapeutic options \\
\hline $\begin{array}{l}\text { Acute and symptomatic hyponatremia } \\
\text { Thiazide-induced hyponatremia }\end{array}$ & $\begin{array}{l}\text { Regardless of cause: hypertonic saline } \\
\text { Isotonic saline, stop diuretic }\end{array}$ \\
$\begin{array}{l}\text { Non-renal sodium loss (gastrointestinal disease, burns) } \\
\text { Congestive heart failure }\end{array}$ & Isotonic saline \\
Liver cirrhosis & Fluid restriction, vasopressin receptor antagonists \\
Adrenal insufficiency & Fluid restriction, vasopressin receptor antagonists \\
Hypothyroidism & Isotonic saline, hydrocortisone \\
Cerebral salt wasting & Thyroid hormone replacement \\
Syndrome of inappropriate antidiuresis (SIAD) & Isotonic saline \\
& Fluid restriction, demeclocycline, urea, $\kappa$-opioid agonist, vasopressin \\
Nephrogenic SIAD & receptor antagonist ${ }^{1}$ \\
Reset osmostat & As SIAD. Especially urea appears effective \\
Low solute intake & No treatment \\
Exercise associated hyponatremia & Increased protein and electrolyte intake \\
Primary polydipsia & If acute: hypertonic saline \\
& If acute: hypertonic saline. Prevention: clozapine
\end{tabular}

${ }^{1}$ Some of these options may also be appropriate in other forms of hyponatremia with an increased extracellular fluid volume.

hyponatremia should be corrected more slowly, especially when risk factors for osmotic demyelination are present such as malnourishment or hypokalemia [64]. However, chronic hyponatremia is not benign and has lost its 'innocence' especially since Decaux [65] asked the cryptic question, 'Is asymptomatic hyponatremia really asymptomatic?' In arguably one of the most important studies on hyponatremia in years, they showed in a 1:2 matched case-control study that chronic hyponatremia was associated with a fourfold increase in falls, and marked gait and attention impairments [66]. Interestingly, the authors postulated that these more subtle neurological symptoms could result from nerve conduction velocity slowing, possibly brought about by a lower electrochemical gradient due to hyponatremia [66].

The armamentarium for hyponatremia consists of isotonic saline, hypertonic saline, water restriction, demeclocycline, urea, and the recently introduced vasopressin receptor antagonists (table 3) [67]. Furthermore, furosemide is often used in combination with one of these therapies to treat volume expansion and stimulate free water clearance. Paradoxically, vasopressin can also be added to the list if the rate of correction is too rapid and needs to be curtailed. The selection of therapy obviously depends on the underlying hyponatremic disorder. Hypertonic saline is most commonly used to correct acute hyponatremia with cerebral edema regardless of the underlying cause, whereas isotonic saline is often used in cases of 'depletional' hyponatremia. Water re- striction, demeclocycline, and urea are recognized therapies for SIAD, while the vasopressin receptor antagonists (also called 'vaptans' or 'aquaretics') have also been registered for SIAD, as well as hyponatremia in heart or liver failure.

To date, four vasopressin receptor antagonists have been developed, including satavaptan, lixivaptan, tolvaptan, and conivaptan, the latter of which also has Vla antagonistic properties [21]. Recently, several studies have shown their efficacy in correcting hyponatremia due to SIAD, heart failure, and liver failure. For example, in the SALT study, tolvaptan produced a rise in serum sodium concentration from approximately 128 to $136 \mathrm{mmol} / \mathrm{l}$ in 10 days in patients with SIAD, heart failure, and liver failure (vs. a surprising rise with placebo from 128 to 132 $\mathrm{mmol} / \mathrm{l}$ ) [68]. A health survey also showed mental but not physical benefits of the drug [68]. In the larger EVEREST trial tolvaptan was given to over 4,000 patients with heart failure in addition to standard therapy, and resulted in weight reduction, a $2-3-\mathrm{mmol} / \mathrm{l}$ increase in serum sodium, more self-reported relief of dyspnea, but no effect on mortality [69].

Several formulae exist to calculate the desired correction rate [for a recent review see 21]. The advantage of the so-called Adrogue-Madias formula, which estimates the effect of 1 liter of a chosen infusate on the serum sodium concentration [2], is that this formula was recently tested in a prospective study and was found to predict the rise in the serum sodium concentration fairly well [70]. An 
important caveat is that the correction as calculated by this formula may be too rapid in patients with extracellular volume depletion who can have sudden water diuresis when the stimulus for vasopressin release abates [70]. To some extent, the rise in serum sodium concentration will always remain unpredictable, and therefore it is recommended not to rely too heavily on predictions based on formulas, but to select the appropriate therapy and monitor the serum sodium concentration, urine output and urine composition frequently.

\section{Perspectives}

In the years to come, the long-term effects of vasopressin receptor antagonists in the treatment of hyponatremia will likely be one of the major topics. Despite their proven efficacy, it remains to be seen what their exact place in the treatment of hyponatremia will become, and their inclusion in treatment algorithms seems somewhat preliminary [21]. It will be interesting to see whether they only increase the serum sodium level, or whether they also affect outcome in heart or liver failure, or whether they might expedite the duration of therapy. Still, their potential dangers should be borne in mind, including the risk of osmotic demyelination with sometimes uncontrollable rises in serum sodium concentration, and potential untoward effects in patients with hypovolemic hyponatremia [71]. In addition to the concept of vasopressin receptor antagonists, it was of interest to learn that the V2R-AQP2 cascade (fig. 1) can also be targeted from the other side by water channel antagonists. In experiments with oocytes, it was shown to be possible to inhibit the AQP water channels with quaternary ammonium compounds, which could be of interest for the future treatment of hyponatremia [72]. Other interesting subjects for future research include the role of osmotically inactive sodium stores in water and sodium balance regulation [59], and the possible role of nerve conduction velocity slowing in the symptomatology of chronic hyponatremia [66]. For the short term, the prevention of hyponatremia and the improvement in its management seem both necessary and achievable goals, especially given the persistently high rates of hospital-acquired hyponatremia with considerable morbidity and mortality $[1,73]$.

\section{References}

$\checkmark 1$ Hoorn EJ, Lindemans J, Zietse R: Development of severe hyponatraemia in hospitalized patients: treatment-related risk factors and inadequate management. Nephrol Dial Transplant 2006;21:70-76.

$\checkmark 2$ Adrogue HJ, Madias NE: Hyponatremia. N Engl J Med 2000;342:1581-1589.

$\checkmark 3$ Adrogue HJ: Consequences of inadequate management of hyponatremia. Am J Nephrol 2005;25:240-249.

$\checkmark 4$ Hoorn EJ, Halperin ML, Zietse R: Diagnostic approach to a patient with hyponatraemia: traditional versus physiology-based options. QJM 2005;98:529-540.

$\checkmark 5$ Bourque CW, Oliet SH: Osmoreceptors in the central nervous system. Annu Rev Physiol 1997;59:601-619.

-6 McKinley MJ, Denton DA, Oldfield BJ, De Oliveira LB, Mathai ML: Water intake and the neural correlates of the consciousness of thirst. Semin Nephrol 2006;26:249-257.

-7 Sharif Naeini R, Witty MF, Seguela P, Bourque CW: An N-terminal variant of Trpvl channel is required for osmosensory transduction. Nat Neurosci 2006;9:93-98.

$>8$ Oliet SH, Bourque CW: Mechanosensitive channels transduce osmosensitivity in supraoptic neurons. Nature 1993;364:341343.
9 Burbach JP, Luckman SM, Murphy D, Gainer $\mathrm{H}$ : Gene regulation in the magnocellular hypothalamo-neurohypophysial system. Physiol Rev 2001;81:1197-1267.

10 Nielsen S, Frokiaer J, Marples D, Kwon TH, Agre P, Knepper MA: Aquaporins in the kidney: from molecules to medicine. Physiol Rev 2002;82:205-244.

11 Bankir L: Antidiuretic action of vasopressin: quantitative aspects and interaction between V1a and V2 receptor-mediated effects. Cardiovasc Res 2001;51:372-390.

12 Umenishi F, Narikiyo T, Vandewalle A, Schrier RW: cAMP regulates vasopressin-induced AQP2 expression via protein kinase A-independent pathway. Biochim Biophys Acta 2006;1758:1100-1105.

13 Chou CL, Christensen BM, Frische S, Vorum H, Desai RA, Hoffert JD, et al: Non-muscle myosin II and myosin light chain kinase are downstream targets for vasopressin signaling in the renal collecting duct. J Biol Chem 2004;279:49026-49035.

14 Anderson RJ, Chung HM, Kluge R, Schrier RW: Hyponatremia: a prospective analysis of its epidemiology and the pathogenetic role of vasopressin. Ann Intern Med 1985;102:164168.
5 Feldman BJ, Rosenthal SM, Vargas GA, Fenwick RG, Huang EA, Matsuda-Abedini M, et al: Nephrogenic syndrome of inappropriate antidiuresis. N Engl J Med 2005;352:18841890.

16 Papanicolaou DA, Wilder RL, Manolagas SC, Chrousos GP: The pathophysiologic roles of interleukin- 6 in human disease. Ann Intern Med 1998;128:127-137.

17 Ghorbel MT, Sharman G, Leroux M, Barrett T, Donovan DM, Becker KG, et al: Microarray analysis reveals interleukin- 6 as a novel secretory product of the hypothalamo-neurohypophyseal system. J Biol Chem 2003; 278:19280-19285.

18 Kurotani R, Yasuda M, Oyama K, Egashira N, Sugaya M, Teramoto A, et al: Expression of interleukin-6, interleukin-6 receptor (gp80), and the receptor's signal-transducing subunit (gp130) in human normal pituitary glands and pituitary adenomas. Mod Pathol 2001;14:791-797.

$\checkmark 19$ Beukhof CM, Hoorn EJ, Lindemans J, Zietse R: Novel risk factors for hospital-acquired hyponatraemia: a matched case-control study. Clin Endocrinol (Oxf) 2007;66:367372 . 
20 Hoorn EJ, Hoffert JD, Knepper MA: Combined proteomics and pathways analysis of collecting duct reveals a protein regulatory network activated in vasopressin escape. J Am Soc Nephrol 2005; 16:2852-2863.

$\checkmark 21$ Ellison DH, Berl T: Clinical practice. The syndrome of inappropriate antidiuresis. N Engl J Med 2007;356:2064-2072.

-22 Hsu YJ, Chiu JS, Lu KC, Chau T, Lin SH: Biochemical and etiological characteristics of acute hyponatremia in the emergency department. J Emerg Med 2005;29:369-374.

-23 Shafiee MA, Charest AF, Cheema-Dhadli S, Glick DN, Napolova O, Roozbeh J, et al: Defining conditions that lead to the retention of water: the importance of the arterial sodium concentration. Kidney Int 2005;67:613-621.

-24 Halperin ML, Kamel KS, Sterns R: Hyponatremia in marathon runners. N Engl J Med 2005;353:427-428.

25 Janicic N, Verbalis JG: Evaluation and management of hypo-osmolality in hospitalized patients. Endocrinol Metab Clin North Am 2003;32:459-481, vii.

\26 Gagnon RF, Halperin ML: Possible mechanisms to explain the absence of hyperkalaemia in Addison's disease. Nephrol Dial Transplant 2001;16:1280-1284.

-27 Smith JC, Siddique H, Corrall RJ: Misinterpretation of serum cortisol in a patient with hyponatraemia. BMJ 2004;328:215-216.

-28 Diederich S, Franzen NF, Bahr V, Oelkers W: Severe hyponatremia due to hypopituitarism with adrenal insufficiency: report on 28 cases. Eur J Endocrinol 2003;148:609-617.

-29 Decaux G, Musch W, Penninckx R, Soupart A: Low plasma bicarbonate level in hyponatremia related to adrenocorticotropin deficiency. J Clin Endocrinol Metab 2003;88: 5255-5257.

-30 Warner MH, Holding S, Kilpatrick ES: The effect of newly diagnosed hypothyroidism on serum sodium concentrations: a retrospective study. Clin Endocrinol (Oxf) 2006; 64:598-599.

-31 Decaux G, Vandergheynst F, Bouko Y, Parma J, Vassart G, Vilain C: Nephrogenic syndrome of inappropriate antidiuresis in adults: high phenotypic variability in men and women from a large pedigree. J Am Soc Nephrol 2007; 18:606-612.

32 Rose BD, Post TW: Clinical Physiology of Acid-Base and Electrolyte Disorders, ed 5. New York, McGraw-Hill, 2001.

-33 Decaux G, Namias B, Gulbis B, Soupart A Evidence in hyponatremia related to inappropriate secretion of $\mathrm{ADH}$ that $\mathrm{V} 1$ receptor stimulation contributes to the increase in renal uric acid clearance. J Am Soc Nephrol 1996;7:805-810.

-34 Maesaka JK, Miyawaki N, Palaia T, Fishbane S, Durham JH: Renal salt wasting without cerebral disease: diagnostic value of urate determinations in hyponatremia. Kidney Int 2007;71:822-826.
35 Maesaka JK, Venkatesan J, Piccione JM, Decker R, Dreisbach AW: Abnormal urate transport in patients with intracranial disease. Am J Kidney Dis 1992;19:10-15.

36 Chung HM, Kluge R, Schrier RW, Anderson RJ: Clinical assessment of extracellular fluid volume in hyponatremia. Am J Med 1987;83: 905-908.

37 McGee S, Abernethy WB 3rd, Simel DL: The rational clinical examination. Is this patient hypovolemic? JAMA 1999;281:1022-1029.

38 Reynolds RM, Padfield PL, Seckl JR: Disorders of sodium balance. BMJ 2006;332:702705 .

39 Carlotti AP, Bohn D, Mallie JP, Halperin ML: Tonicity balance, and not electrolyte-free water calculations, more accurately guides therapy for acute changes in natremia. Intensive Care Med 2001;27:921-924.

40 Turchin A, Seifter JL, Seely EW: Clinical problem-solving. Mind the gap. N Engl J Med 2003;349:1465-1469.

41 Aw TC, Kiechle FL: Pseudohyponatremia. Am J Emerg Med 1985;3:236-239.

42 Hillier TA, Abbott RD, Barrett EJ: Hyponatremia: evaluating the correction factor for hyperglycemia. Am J Med 1999;106:399403.

43 Hamburger S, Koprivica B, Ellerbeck E, Covinsky JO: Thiazide-induced syndrome of inappropriate secretion of antidiuretic hormone. Time course of resolution. JAMA 1981;246:1235-1236.

44 Sonnenblick M, Friedlander Y, Rosin AJ: Diuretic-induced severe hyponatremia. Review and analysis of 129 reported patients. Chest 1993;103:601-606.

45 Chow KM, Szeto CC, Wong TY, Leung CB, Li PK: Risk factors for thiazide-induced hyponatraemia. QJM 2003;96:911-917.

46 Friedman E, Shadel M, Halkin H, Farfel Z: Thiazide-induced hyponatremia. Reproducibility by single dose rechallenge and an analysis of pathogenesis. Ann Intern Med 1989;110:24-30.

47 Robertson GL: Regulation of arginine vasopressin in the syndrome of inappropriate antidiuresis. Am J Med 2006;119(suppl 1):S36S42.

48 Berendes E, Walter M, Cullen P, Prien T, Van Aken H, Horsthemke J, et al: Secretion of brain natriuretic peptide in patients with aneurysmal subarachnoid haemorrhage. Lancet 1997;349:245-249.

49 Schrier RW: Pathogenesis of sodium and water retention in high-output and low-output cardiac failure, nephrotic syndrome, cirrhosis, and pregnancy (1). N Engl J Med 1988; 319:1065-1072.

50 Schrier RW: Pathogenesis of sodium and water retention in high-output and low-output cardiac failure, nephrotic syndrome, cirrhosis, and pregnancy (2). N Engl J Med 1988; 319:1127-1134.
Lee DS, Austin PC, Rouleau JL, Liu PP, Naimark D, Tu JV: Predicting mortality among patients hospitalized for heart failure: derivation and validation of a clinical model. JAMA 2003;290:2581-2587.

52 Londono MC, Guevara M, Rimola A, Navasa M, Taura P, Mas A, et al: Hyponatremia impairs early posttransplantation outcome in patients with cirrhosis undergoing liver transplantation. Gastroenterology 2006;130 1135-1143.

53 Goldberg A, Hammerman H, Petcherski S, Nassar M, Zdorovyak A, Yalonetsky S, Kapeliovich $\mathrm{M}$, et al: Hyponatremia and longterm mortality in survivors of acute ST-elevation myocardial infarction. Arch Intern Med 2006;166:781-786.

54 Dzau VJ, Packer M, Lilly LS, Swartz SL, Hollenberg NK, Williams GH: Prostaglandins in severe congestive heart failure. Relation to activation of the renin-angiotensin system and hyponatremia. N Engl J Med 1984;310: 347-352.

55 Porcel A, Diaz F, Rendon P, Macias M, Martin-Herrera L, Giron-Gonzalez JA: Dilutional hyponatremia in patients with cirrhosis and ascites. Arch Intern Med 2002;162:323328 .

56 Hoorn EJ, Lindemans J, Zietse R: Acute and concomitant deterioration of hyponatremia and renal dysfunction associated with heart and liver failure. Clin Nephrol 2006;65:248255

57 Noakes TD, Goodwin N, Rayner BL, Branken T, Taylor RK: Water intoxication: a possible complication during endurance exercise. Med Sci Sports Exerc 1985;17:370-375.

58 Almond CS, Shin AY, Fortescue EB, Mannix RC, Wypij D, Binstadt DA, Duncan CN, et al: Hyponatremia among runners in the Boston Marathon. N Engl J Med 2005;352:15501556.

59 Noakes TD, Sharwood K, Speedy D, Hew T, Reid S, Dugas J, et al: Three independent biological mechanisms cause exercise-associated hyponatremia: evidence from 2,135 weighed competitive athletic performances. Proc Natl Acad Sci USA 2005;102:1855018555.

60 Knochel JP, Dotin LN, Hamburger RJ: Pathophysiology of intense physical conditioning in a hot climate. I. Mechanisms of potassium depletion. J Clin Invest 1972;51:242-255.

61 Siegel AJ, Verbalis JG, Clement S, Mendelson JH, Mello NK, Adner M, et al: Hyponatremia in marathon runners due to inappropriate arginine vasopressin secretion. Am J Med 2007;120:461.e11-461.e17.

62 Thaler SM, Teitelbaum I, Berl T: 'Beer potomania' in non-beer drinkers: effect of low dietary solute intake. Am J Kidney Dis 1998;31: 1028-1031.

63 Musch W, Xhaet O, Decaux G: Solute loss plays a major role in polydipsia-related hyponatraemia of both water drinkers and beer drinkers. QJM 2003;96:421-426. 
64 Lohr JW: Osmotic demyelination syndrome following correction of hyponatremia: association with hypokalemia. Am J Med 1994; 96:408-413.

65 Decaux G: Is asymptomatic hyponatremia really asymptomatic? Am J Med 2006;119: S79-S82.

-66 Renneboog B, Musch W, Vandemergel X, Manto MU, Decaux G: Mild chronic hyponatremia is associated with falls, unsteadiness, and attention deficits. Am J Med 2006; 119:71.e1-71.e8.

67 Verbalis JG, Goldsmith SR, Greenberg A, Schrier RW, Sterns RH: Hyponatremia treatment guidelines 2007: expert panel recommendations. Am J Med 2007;120(suppl 1): S1-S21.
68 Schrier RW, Gross P, Gheorghiade M, Berl T, Verbalis JG, Czerwiec FS, et al: Tolvaptan, a selective oral vasopressin V2-receptor antagonist, for hyponatremia. N Engl J Med 2006;355:2099-2112.

69 Gheorghiade M, Konstam MA, Burnett JC Jr, Grinfeld L, Maggioni AP, Swedberg K, et al: Short-term clinical effects of tolvaptan, an oral vasopressin antagonist, in patients hospitalized for heart failure: the EVEREST Clinical Status Trials. JAMA 2007;297:13321343.

70 Liamis G, Kalogirou M, Saugos V, Elisaf M: Therapeutic approach in patients with dysnatraemias. Nephrol Dial Transplant 2006; 21:1564-1569.
71 Hoorn EJ, Zietse R: Tolvaptan for hyponatremia. N Engl J Med 2007;356:961; author reply 962-963.

72 Detmers FJ, de Groot BL, Muller EM, Hinton A, Konings IB, Sze M, et al: Quaternary ammonium compounds as water channel blockers. Specificity, potency, and site of action. J Biol Chem 2006;281:14207-14214.

73 Moritz ML, Ayus JC: Hospital-acquired hyponatremia: why are there still deaths? Pediatrics 2004;113:1395-1396.

74 Patel GP, Balk RA: Recognition and treatment of hyponatremia in acutely ill hospitalized patients. Clin Ther 2007;29:211-229. 